\title{
A Thirty-Four-Year-Old Woman with Chronic Dyspnea and Pulmonary Interlobular Septal Thickening
}

\author{
Manuel L. Ribeiro Neto ${ }^{a}$ Andrea Arrossi ${ }^{b}$ Ashish Maskey ${ }^{c}$ Ruchi Yadav ${ }^{d}$ \\ Gustavo A. Heresi ${ }^{\mathrm{a}}$ \\ ${ }^{a}$ Respiratory Institute, ${ }^{b}$ Pathology Institute and ${ }^{C}$ Imaging Institute, The Cleveland Clinic Foundation, Cleveland, Ohio, \\ and ${ }^{\mathrm{d}}$ Pulmonary Division, Beth Israel Deaconess Medical Center, Boston, Mass., USA
}

A 34-year-old woman presented to our emergency department with profound dyspnea, present even at rest, associated with orthopnea, lower extremity edema and weight gain. She had first noticed dyspnea on exertion 1 year previously. She had recently been prescribed supplemental oxygen via nasal cannula in December 2009.

Her past medical history was complex and significant for: (1) recurrent pancreatitis; (2) a minimally functional left kidney secondary to chronic perinephric inflammation of unclear etiology; (3) visual loss with papilledema which required bilateral optic nerve sheath decompression in July 2008, and (4) and autoimmune hemolytic anemia following red blood cell transfusion.

Upon presentation, her blood pressure was 152/84 $\mathrm{mm} \mathrm{Hg}$, with a heart rate of 60 beats/min. She was breathing at a rate of 28 breaths/min and her oxygen saturation was $80 \%$ on 4 liters/min of oxygen via nasal cannula. She was obese, had a right lower eyelid xanthelasma, and we were unable to assess for jugular vein distention. She had bibasilar rales on lung exam, a regular rate and rhythm without murmurs or gallops on heart exam, and a nontender abdomen without organomegaly. On her extremities, she had bilateral $2+$ pitting edema without clubbing.

Complete blood count revealed a white cell count of $13,000 / \mathrm{mm}^{3}$ and a platelet count of $599,000 / \mathrm{mm}^{3}$. Hemo- globin was normal. Relevant basic metabolic panel results were: creatinine $1.36 \mathrm{mg} / \mathrm{dl}$ (baseline 1.3) and bicarbonate $35 \mathrm{mg} / \mathrm{dl}$. Urinalysis was normal. Arterial blood gases (in the emergency department on the 50\% Venturi Mask) revealed: $\mathrm{pH} 7.33, \mathrm{pCO}_{2} 65, \mathrm{pO}_{2} 74$ and oxyhemoglobin $92 \%$.

Chest radiograph and computed tomography (CT) scan at presentation are shown in figure 1. Two-dimensional echocardiogram revealed normal left ventricular size and systolic function, mild diastolic dysfunction and no significant valvular abnormalities. Subsequent radiographs of the lower limbs (fig. 2) showed significant osteosclerosis of the tibia and fibula, with sparing of the epiphyses and less pronounced femoral involvement.

The patient was admitted to the medical intensive care unit requiring intubation and mechanical ventilation in February 2010. Despite aggressive management of volume overload from the 3rd to the 16th of February 2010, the lung parenchyma abnormalities persisted. A pulmonary artery catheter showed a mean pulmonary pressure of $36 \mathrm{~mm} \mathrm{Hg}$, a pulmonary artery occlusion pressure of $15 \mathrm{~mm} \mathrm{Hg}$ and a normal cardiac output. She subsequently underwent a surgical lung biopsy.

What is your diagnosis?

\section{KARGER}

E-Mail karger@karger.com

www.karger.com/res
(C) 2013 S. Karger AG, Basel

0025-7931/13/0861-0072\$38.00/0
Gustavo A. Heresi

The Cleveland Clinic Foundation

9500 Euclid Avenue/A90

Cleveland, Ohio 44195 (USA)

E-Mail heresig@ccf.org 


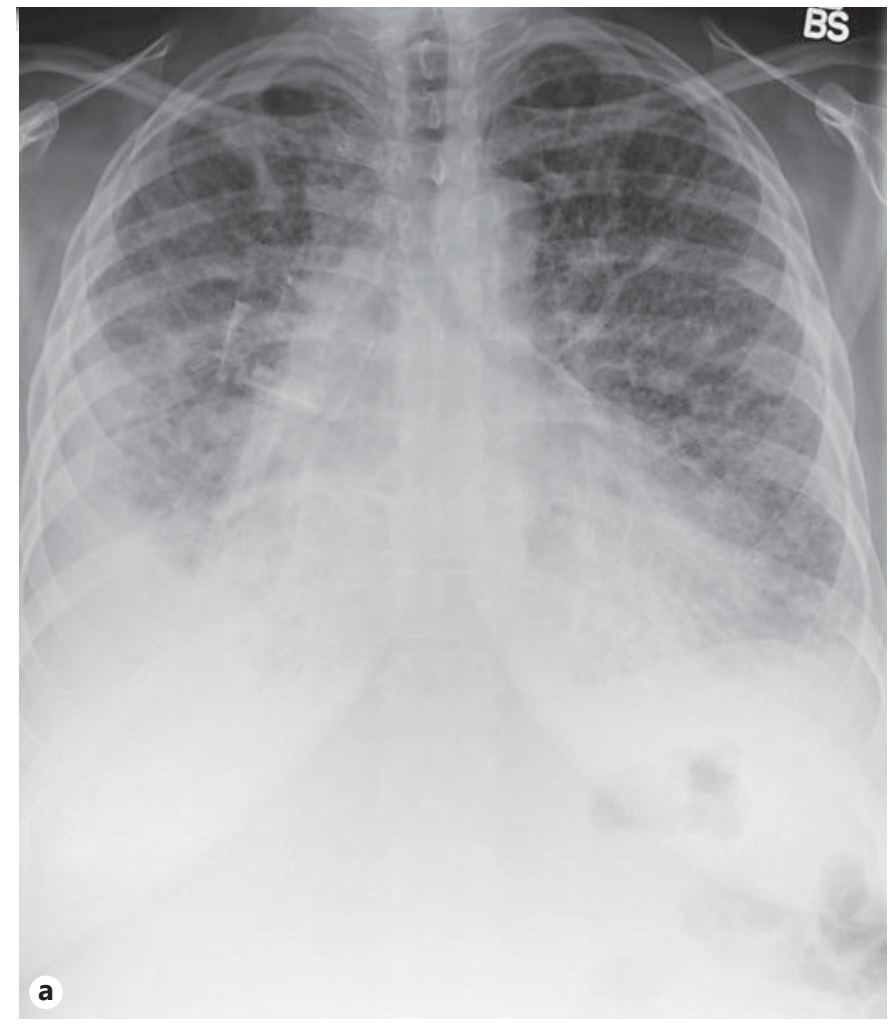

Fig. 1. a Chest radiograph reveals enlarged cardiac silhouette, medium right and small left pleural effusions and diffuse reticular interstitial process. b, $\mathbf{c}$ Chest CT scan shows diffuse smooth interlobular septal thickening (arrowheads), patchy regions of groundglass attenuation (thick arrow), small right pleural effusion and fissural thickening (thin arrow).

Fig. 2. Radiograph of the lower extremities demonstrates metadiaphyseal osteosclerosis involving both tibias.
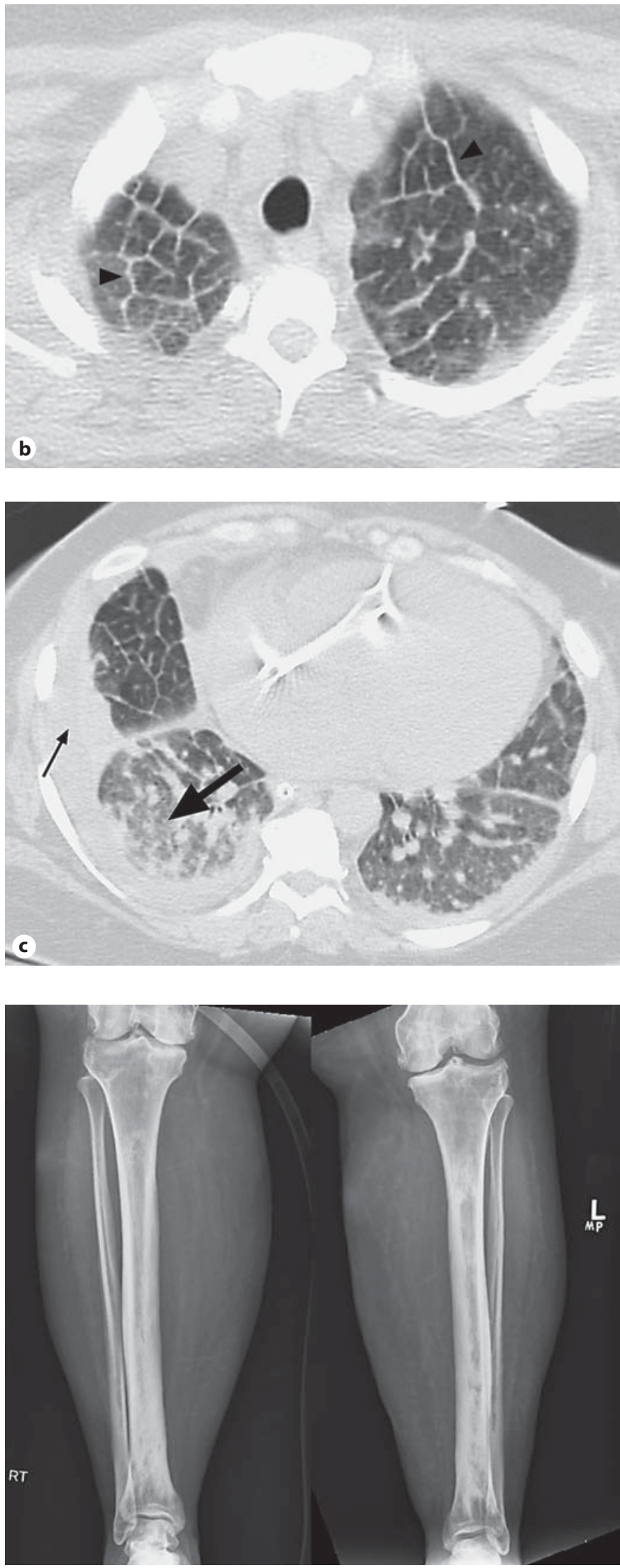

Respiration 2013;86:72-75 


\section{Diagnosis: Erdheim-Chester Disease}

\section{Clinical Course}

Surgical lung biopsy was consistent with ErdheimChester disease (ECD) (fig. 3). The patient was started on high-dose corticosteroids on 20 February 2010 and she was eventually weaned off the mechanical ventilation on 22 February and discharged from the hospital in March.
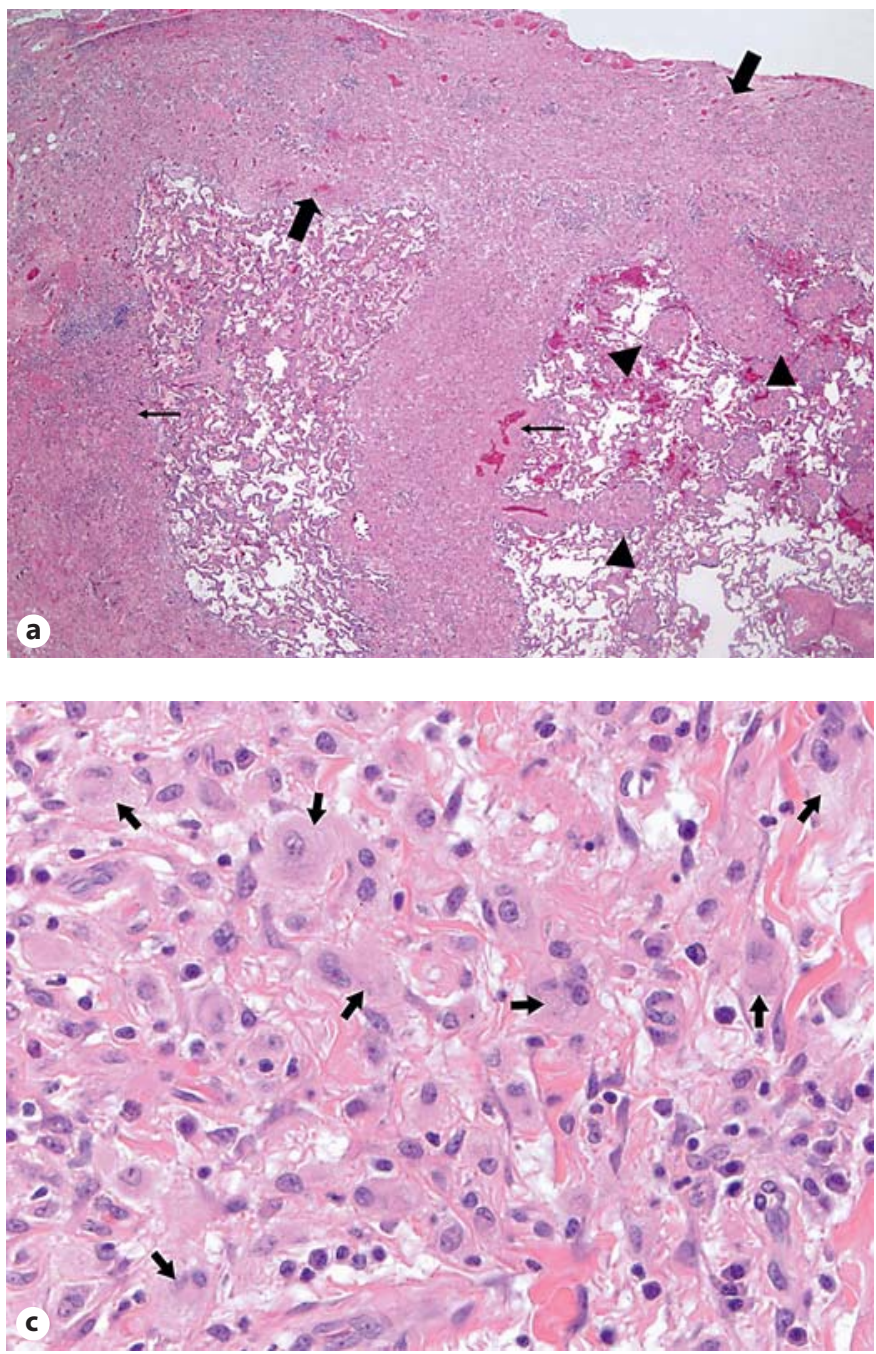

Fig. 3. a Scanning view of lung with thickening of the pleura (thick arrows), interlobular septa (thin arrows) and perivascular spaces (arrowheads). HE. $\times 2$. b Intermediate magnification view of a perivascular space with infiltration of histiocytes (thick arrows) accompanied by mixed inflammatory cells, lymphocytes, plasma
A left nephrectomy was performed a few months later in January 2011; this showed extensive xanthogranulomatous histiocytic infiltration with fibrosis, also consistent with ECD.

After multiple episodes of respiratory failure, she died on 14 February 2011, a year after the diagnosis was made.
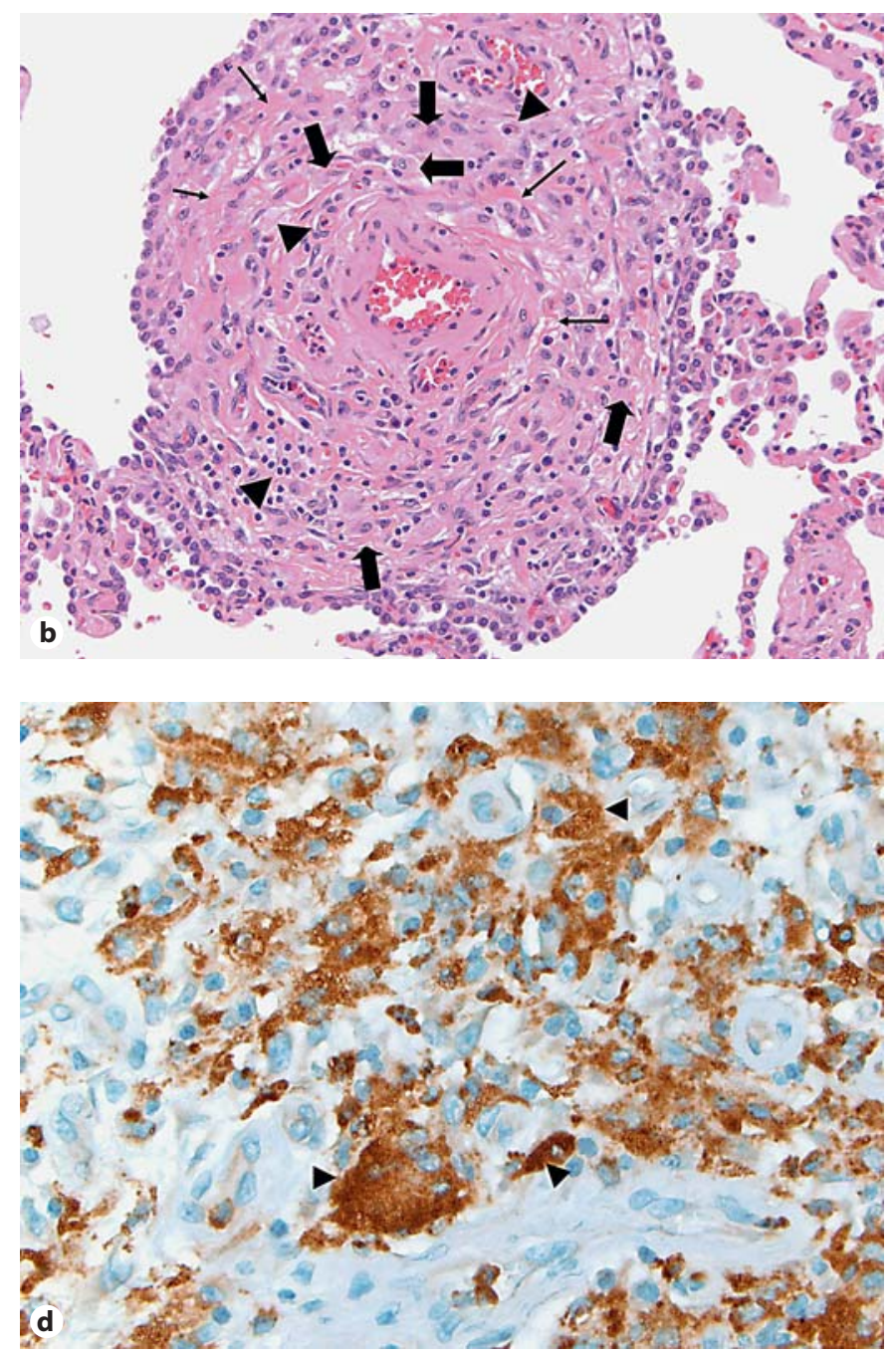

cells and eosinophils (arrowheads) and collagen fibers (thin arrows). HE. $\times 20$. c High power showing histiocytes with eosinophilic to foamy cytoplasm (thick arrows). HE. $\times 40$. d Histiocytes immunoreactive to CD68 (arrowheads). CD68. $\times 40$. 


\section{Discussion}

ECD is a rare non-Langerhans cell histiocytosis of unknown etiology, characterized by a histiocytic infiltration of several tissues (including skin, retro-orbital tissue, pericardium, lung, retroperitoneum, kidneys, bone and the central nervous system). The histiocytes found in the tissues in ECD belong to the group of tissue histiocytes (interstitial dendritic cells and macrophages) that present antigens to $\mathrm{T}$ cells and are derived from the blood precursor monocyte. These histiocytes are positive for CD14, CD68 and CD163 and negative for CD1a, S100 and langerin. The etiology of ECD is unknown, but recent data demonstrate that ECD lesions express a wide array of cytochemokines, which may orchestrate histiocyte recruitment and activation $[1,2]$.

An analysis of 59 patients with ECD by Veyssier-Belot et al. [3] provided a good description of the clinical features of this form of histiocytosis. The mean age at diagnosis was 55 years and there was a slight male predominance (55\% male vs. $45 \%$ female). Bone pain was the most frequent symptom ( $47 \%$ of patients), and it mainly affected the lower limbs. It was followed by diabetes insipidus, retroperitoneum and kidney involvement (28\%), and exophthalmos (27\%), which, in 7 patients, occurred many years before the diagnosis. Other less common findings included fever, weight loss, xanthomas, pericardial effusion, hepatosplenomegaly and ataxia.

The prevalence of lung involvement is variable in the literature $[1,4-6]$. One case series reported $53 \%$ of patients having lung involvement [6]. The most common parenchymal findings included interlobular septal thickening (32\%), centrilobular nodules $(21 \%)$, ground-glass opacities (12\%), thickening of interlobar fissures (12\%), consolidations (9\%) and thin-walled cysts (6\%). Pleural findings were thickening (24\%) and effusions (21\%). Histologically, the lung is infiltrated by numerous histiocytes in subpleural, paraseptal and perivascular areas (fig. 3), consistent with a lymphatic distribution, as seen in the surgical lung biopsy in this particular patient. The histiocytes have foamy-to-clear cytoplasm and are associated with variable amounts of fibrosis.

The diagnosis of ECD can be challenging because diagnostic criteria have not been established. Veyssier-Belot et al. [3] suggested considering: (1) clinical symptoms and signs consistent with ECD; (2) typical findings in bone radiographs characterized by symmetric osteosclerosis of the long bones and spared flat bones and appendicular skeleton, and (3) pathological findings consistent with ECD [1]. Systemic corticosteroids, cyclosporine, interferon-alpha, chemotherapy, radiation therapy and surgical procedures have been used to treat $\mathrm{ECD}$, with a variable response in the literature $[1,7,8]$. There is also uncertainty with regard to the natural history and prognosis of this disease. Initial analysis of case reports suggested a 3-year mortality rate of $57 \%$ [3], but a more recent case series of consecutive patients reported a 13 -year mortality rate of $26 \%$ [6]. It is not known if pulmonary involvement constitutes a prognostic factor $[1,6,9]$.

\section{Key Words}

Interstitial lung diseases $\cdot$ Erdheim-Chester disease $\cdot$ Histiocytosis

\section{References}

$>1$ Shamburek RD, Brewer B Jr, Gochuico BR: Erdheim-Chester disease: a rare multisytem histiocytic disorder associated with interstitial lung disease. Am J Med Sci 2001;321:6675.

-2 Mills JA, Gonzalez G, Jaffe R: Case 25-2008: a 43-year-old man with fatigue and lesions in the pituitary and cerebellum. N Engl J Med 2008;359:736-747.

-3 Veyssier-Belot C, Cacoub P, Caparros-Lefebvre D, Wechsler J, Brun B, Remy M, Wallaert B, Petit H, Grimaldi A, Wechsler B, Godeau P: Erdheim-Chester disease: clinical and radiologic characteristics of 59 cases. Medicine 1996;75:157-169.
4 Yamaguchi M, Shiota T, Kobashi Y: ErdheimChester disease presenting with pneumothorax. Respiration 2011;82:552-556.

5 Wittenberg KH, Swensen SJ, Myers JL: Pulmonary Involvement with Erdheim-Chester disease: radiographic and CT findings. AJR 2000;174:1327-1331.

6 Arnaud L, Pierre I, Beigelman-Aubry C, Capron F, Brun AL, Rigolet A, Girerd X, Weber N, Piette JC, Grenier PA, Amoura, Haroche $\mathrm{J}$ : Pulmonary involvement in Erdheim-Chester disease. A single-center study of thirtyfour patients and a review of the literature. Arthritis Rheum 2010;62:3504-3512.

7 Braiteh F, Boxrud C, Esmaeli C, Kurzrock R: Successful treatment of Erdheim-Chester disease, a non-Langerhans-cell histiocytosis, with interferon-alpha. Blood 2005;106:2992-2994.
8 Haroche J, Amoura Z, Trad SG, Wechsler B, Cluzel P, Grenier PA, Piette JC: Variability in the efficacy of interferon-alpha in ErdheimChester disease by patient and site of involvement: result in eight patients. Arthritis Rheum 2006;54:3330-3336.

9 Protopapadakis C, Antoniou KM, Nicholson AG, Voloudaki A, Tzanakis N, Karantanas A, Siafakas NM: Erdheim-Chester disease: pulmonary presentation in a case with advanced systemic involvement. Respiration 2009;77: 337-340.
Chronic Dyspnea and Pulmonary

Interlobular Septal Thickening 